\title{
Pathophysiology of heart failure
}

\author{
E Erdmann
}

The 1995 World Health Organisation definition of heart failure has two components: a clinical and a pathophysiological definition. ${ }^{1}$ The pathophysiological definition of heart failure states that "cardiac failure is an inability of the heart to deliver blood (and therefore oxygen) at a rate commensurate with the requirements of the metabolising tissues at rest or during light exercise. This leads to characteristic systemic pathophysiological responses (neural, hormonal, renal and others), symptoms and signs." However, there is now good agreement that heart failure is not simply associated with a loss of contractile cardiac muscle, but that it is more importantly the consequence of alterations of signal transduction and of defects in regulation of force of contraction.

\section{Alterations of $\beta$ adrenergic regulation of cardiac contraction}

The loss of pump function in the early stages of heart failure results in neurosympathetic activation characterised by increased concentrations of noradrenaline and angiotensin II in the blood. The resulting vasoconstriction increases afterload, and their neuroendocrine effects on the kidney increases preload (fig 1).

Within the myocardial cells themselves, sympathetic activation downregulates $\beta$ adrenoceptors, it increases $G$ proteins and thereby reduces intracellular cAMP concentrations. ${ }^{2}$ Recent investigations have shown that these effects are accompanied by decreased concentrations of the mRNA that forms $\beta_{1}$ adrenoceptors, and by increased concentrations of the mRNA that forms $\beta$ adrenoceptor kinase (fig 2). At the biochemical level there is a reduced density of $\beta_{1}$ adrenoceptors in the myocardial cell membrane, and a twofold increase in the concentration of $\beta$ adrenoceptor kinase. ${ }^{3}$ The net outcome is that the $\beta$ adrenoceptor adenyl cyclase system is changed in a way that protects the cell from constant stimulation by noradrenaline.

It has long been recognised that therapeutic interventions that increase intracellular cAMP long term, such as the $\beta$ adrenoceptor agonists (dobutamine), partial agonists (xamoterol) or phosphodiesterase inhibitors (milrinone), are associated with a poor prognosis. It is therefore possible to speculate that the most appropriate treatment might be to administer positive inotropic agents in an attempt to overcome the defects in myocyte signal transduction, and that drugs that increase intracellular cAMP should be avoided.

\section{Alterations of intracellular calcium homeostasis}

Beuckelmann et al have reported that the action potential duration is increased in human heart failure. ${ }^{45}$ This is the consequence of a slower reuptake of calcium by the sarcoplasmic reticulum (SR) during diastole. Recent studies have demonstrated that patients with heart failure have normal protein concentrations of SERCA II and phospholamban, but myocardial calcium uptake and calcium ATPase activity within SR are reduced. ${ }^{67}$

The reduction in SR calcium ATPase activity in the myocardial cell has been shown to be directly related to the reduction in contractile force. ${ }^{8}$ These findings suggest that in patients with heart failure, the SR is unable to release enough calcium during systole because insufficient calcium was taken up during the previous diastole. ${ }^{9}$ It follows that if the decreased functional capacity of the SR to reuptake calcium during diastole is central to the mechanism, then the cytoplasm would be expected to more or less constantly contain increased concentrations of calcium. Although, this is

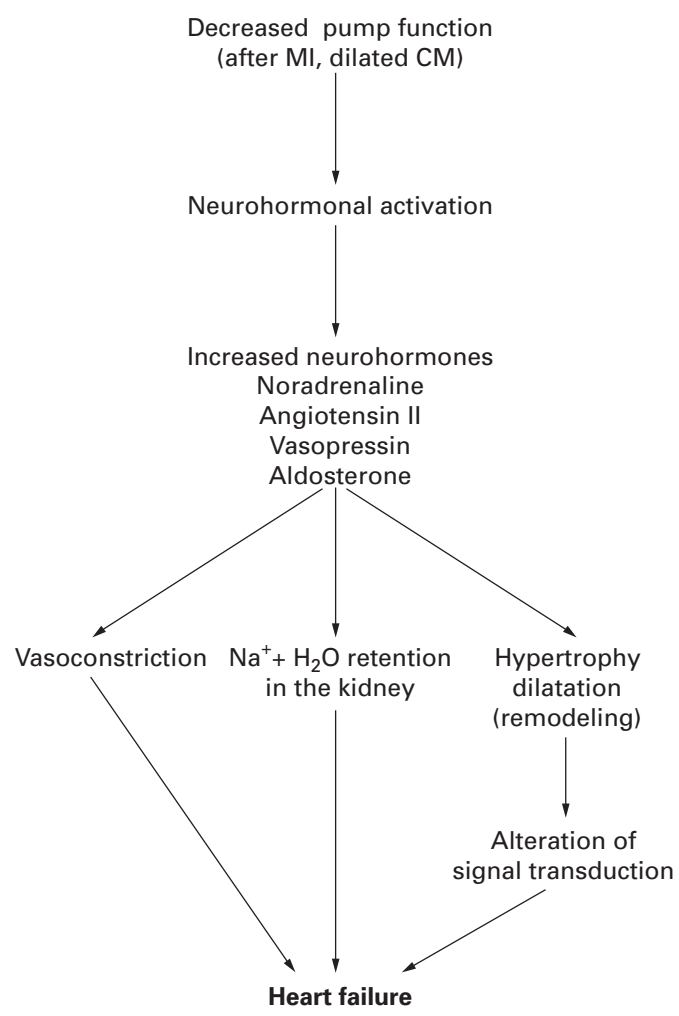

Figure 1 Representation of the neuroendocrine effects on the pathophysiology of heart failure. MI, myocardial infarction; CM, cardiomegaly. 


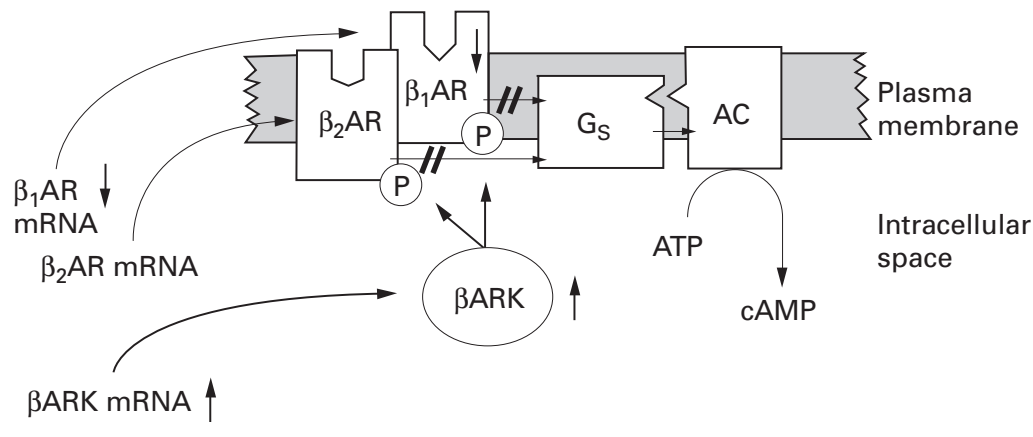

Figure 2 Representation of the molecular changes in severe heart failure that affect the $\beta$ adrenoceptor adenyl cyclase system in human cardiac cells. $\beta_{1} A R, \beta_{1}$ adrenoceptor; $G s$, stimulating $G$ protein; $A C$, adenyl cyclase; $\beta A R K, \beta$ adrenoceptor kinase; $\uparrow$, increases with heart failure; $\downarrow$, decreases with heart failure. Reproduced from Ungerer $M$, Böhm $M$, Elce FS, et al. Circulation 1993;87:454-63 with the permission of the American Heart Association.

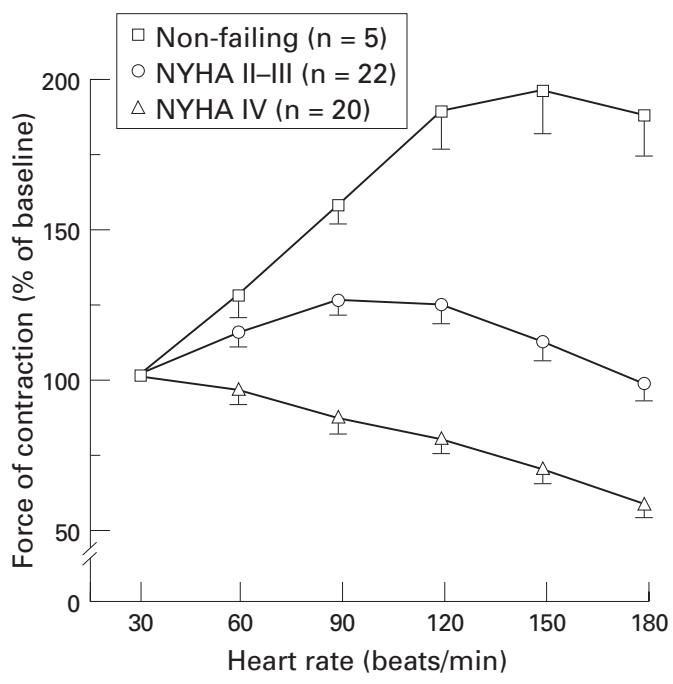

true to some extent, there is no evidence to show that the cytoplasmic calcium concentrations are noticeably increased in patients with heart failure.

Recent investigations have also revealed that the activity of the sarcolemmal sodiumcalcium exchanger is increased in heart failure. This finding supports the hypothesis that there is increased extrusion of cellular calcium ions via the sodium-calcium exchanger during diastole. The sodium-calcium exchanger may, therefore, be an adaptive mechanism that serves to maintain cellular calcium homeostasis in the presence of inadequate SR function during relaxation. ${ }^{5}$ If this is the case it would seem counterproductive to stimulate the failing myocardium by further increasing intracellular calcium concentrations - all positive inotropic agents other than the calcium sensitisers do this, and so far none of this group of agents has been shown to prolong life in patients with heart failure.

\section{The force-frequency relation}

Bowditch was the first to demonstrate experimentally that an increased frequency of stimulation leads to an increased force of contraction in isolated heart preparations (fig 3).${ }^{10}$ It is now widely accepted that most mammals show this positive force-frequency relation (the Bowditch effect). However, it has been shown, using isolated left ventricular muscle preparations from patients with dilated cardiomyopathy, that the force of contraction does not increase significantly at higher rates of stimulation. ${ }^{11-14}$ The Bowditch effect does not, therefore, apply to patients with severe

Figure 3 Example of the Bowditch effect showing increased force of contraction with increased frequency of stimulation.
Figure 4 Force-frequency relation in human papillary muscle in vitro.

heart failure. The reason for this is not fully understood. It is possible that the decreased activity of calcium ATPase within the SR that typifies heart failure is most noticeable in terms of decreasing calcium ion reuptake as diastole becomes shorter during higher frequencies of stimulation. ${ }^{1516}$ Whatever the mechanism, the important finding in severe heart failure is that the force of each single beat decreases severely as the pulse rate increases (fig 4). Thus, interventions that increase heart rate will tend to reduce cardiac output. ${ }^{13}$

Almost all positive inotropic drugs increase heart rate. The same seems to be true for all phoshodiesterase inhibitors, as well as for intermittent dobutamine treatment. One possibility is that the cardiac muscle becomes exhausted more rapidly under these conditions. It has also been speculated that the partial agonist xamoterol, which increases heart rate at night or during rest, shortens lifespan because of this effect. These findings add to the precautions that need to be taken before prescribing positive inotropic agents to patients with heart failure.

\section{Conclusions}

Figure 5 summarises the current state of knowledge about the pathophysiology of heart failure. The observation that increased high heart rate reduces the force of contraction and decreases cardiac output in severe heart failure provides a rationale for using agents that slow heart rate. Indeed, the beneficial effects of $\beta$ adrenoceptor antagonists in patients with heart failure may well be attributed to such an effect. ${ }^{17}$ Prolongation of diastole allows the SR calcium ATPase to pump more calcium into the SR, so that more calcium is available for release during systole. This would facilitate contraction of more adequate force and allow the heart to work more efficiently.

Although existing experimental and clinical evidence supports this concept, it is necessary to realise that high concentrations of $\beta$ block-

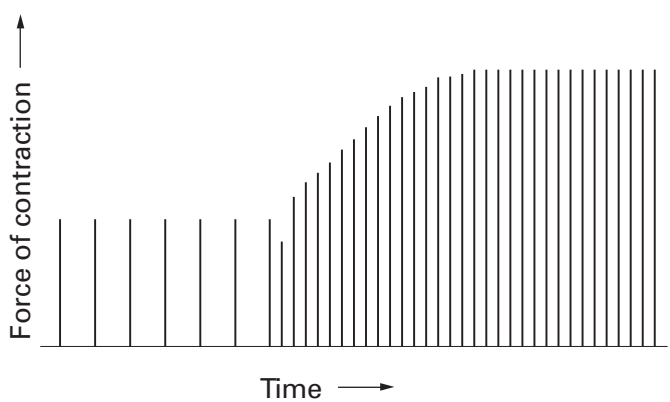


Figure 5 Proposed biochemical basis for heart failure.
Neurohormonal activation

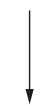

Downregulation of $\beta$ adrenoceptors increased $G_{i}$ proteins

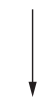

Decreased intracellular cAMP

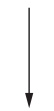

Decreased SERCA II activity

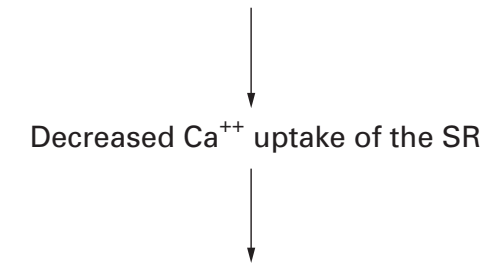

Systolic and diastolic dysfunction

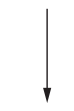

Negative Bowditch effect (force decreases at high heart rates)

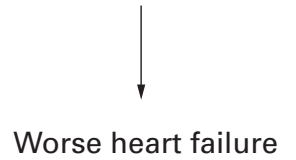

ers may initially have a strong cardiodepressent effect mediated by blockade of the positive inotropic actions of physiologically released noradrenaline.

1 Richardson P, McKenna W, Bristow M, et al. Report on the 1995 World Health Organisation/International
Society and Federation of Cardiology Task Force on the definition and classification of cardiomyopathies. Circulation 1996;93:841-2.

2 Böhm M, Gierschik P, Jakobs K-H, et al. Increase of $\mathrm{G}_{\mathrm{i} \text { in }}$ human heart with dilated but not ischemic cardiomyopathy. Circulation 1990;82:1249-65.

3 Ungerer NI, Böhm M, Elce JS, et al. Altered expression in $\beta$ adrenergic receptor kinase and $\beta_{1}$-adrenergic receptors in the failing human heart. Circulation 1993;87:454-63.

4 Beuckelmann DJ, Näbauer M, Erdmann E. Intracellula calcium handling in isolated ventricular myocytes from patients with terminal heart failure Circulation 1992; patients with

5 Beuckelmaun DJ, Näbauer M, Krüger C, et al. Altered diastolic $\left[\mathrm{Ca}^{2+}\right]$ handling in human ventricular myocytes from patients with terminal heart failure. Am Heart $f$ 1995;129:684-9.

6 Flesch M, Schwingcr RHG, Schnabel P, et al. Sarcoplasmic reticulum $\mathrm{Ca}^{2+}$ ATPase and phospholamban mRNA and protein levels in end-stage heart failure due to ischemic or dilated cardioymopathy. $\mathrm{F} \mathrm{Mol} \mathrm{Med}$. [In press.]

7 Schwinger RHG, Böhm M, Schmidt U, et al. Unchanged protein levels of SERCA II and phospholamban but reduced $\mathrm{Ca}^{2+}$ uptake and $\mathrm{Ca}^{2+}$-ATPase activity of cardiac sarcoplasmic reticulum from dilated cardiomyopathy sarcoplasmic reticulum from dilated cardiomyopathy
patients compared with patients with nonfailing hearts. patients compared with patien

8 Pieske B, Kretschmann B, Meyer M, et al. Alterations in intracellular calcium handling associated with the inverse force-frequency relation in human dilated cardiomyopathy. Circulation 1995;92:1169-78.

9 Field ML, Azzawi A, Unitt JF, et al. Intracellular $\left[\mathrm{Ca}^{2+}\right.$ staircase in the isovolumic pressure-frequency relationship of Langendorff-perfused rat heart. $\mathcal{F}$ Mol Cell Cardio 1996;28:65-77.

10 Bowditch H.P. Über die Eigenthümlichkeiten der Reizbarkeit, welche die Muskelfasern des Herzens zeigen Ber Verh Kgl. Sächs Ges Wiss Leipzig 1987;23:652.

11 Buckley NM, Penefsky ZJ, Litwak RS. Comparative forcefrequency relationships in human and other mammalian frequency relationships in human and other mammalian

12 Feldman MD, Alderman JD, Aroesty JM, et al. Depression of systolic and diastolic myocardial reserve during atrial pacing tachycardia in patients with dilated cardiomyopathy. $\mathcal{F}$ Clin Invest $1988 ; 82: 1661-9$

13 Hasenfuss G, Holubarsch C, Hermann H-P, et al. Influence of the force-frequency relationship on haemodynamics and left ventricular function in patients with non-failing hearts and in patients with dilated cardiomyopathy. Eur Heart f 1994;15:164-70.

14 Schmidt U, Hajiar RI, Gwathmey JK. The force-interval relationship in human myocardium. $f$ Cardiac Failure 1995;4:311-21.

15 Schwinger RHG, Böhm M., Müller-Ehmsen J, et al. Effect of inotropic stimulation on the negative force-frequency relationship in the failing human heart. Circulation relationship in the

16 Schwinger RHG, Böhm M, Erdmann E. Inotropic and lusitropic dysfunction in myocardium from patients with dilated cardiomyopathy Am Heart f 1992;123:116-28.

17 Packer M, Bristow MR, Cohn JN, et al. The effect of carvedilol on morbidity and mortality in patients with chronic heart failure. N Engl f Med 1996;334:1349-55. 